\title{
Expansão de Lesão da Mancha-Reticular da Cevada e sua Interação com o Tratamento de Sementes*
}

\author{
Ana P. Menegon ${ }^{1}$, Carlos A. Forcelini' ${ }^{1}$ \& José M. C. Fernandes ${ }^{2}$ \\ ${ }^{1}$ Faculdade de Agronomia e Medicina Veterinária, Universidade de Passo Fundo, Cx. Postal 611, CEP 99001-970, Passo \\ Fundo, RS, fax: (54) 311-1307, e-mail: forcelini@upf.br; ${ }^{2}$ Embrapa Trigo, CEP 99001-970, Passo Fundo, RS
}

(Aceito para publicação em 01/02/2005)

Autor para correspondência: Carlos Alberto Forcelini

MENEGON, A.P., FORCELINI, C.A. \& FERNANDES, J.M.C. Expansão de lesão da mancha-reticular da cevada e sua interação com o tratamento de sementes. Fitopatologia Brasileira 30:139-142. 2005.

\section{RESUMO}

Experimentos foram conduzidos na FAMV/UPF, em 2002, com o objetivo de avaliar a influência do tratamento de sementes no processo de expansão de lesão pela mancha-reticular da cevada (Hordeum vulgare). Utilizaram-se as cultivares BR 2 e MN 698, com e sem tratamento de sementes com o fungicida triadimenol (40 g i.a./100 kg sementes), combinado com aplicações foliares de um fungicida triazol (tebuconazole) e uma combinação de triazól e estrobirulina (epoxiconazole + piraclostrobim), sob uma ou duas aplicações, em diferentes estádios fenológicos da planta. O tamanho das lesões e a severidade da doença foram avaliadas aos 62, 79, 88, 95, 103 e 111 dias após a semeadura. O tamanho da lesão foi significativamente menor nas plantas a partir de sementes com baixa incidência do patógeno, de sementes tratadas e plantas pulverizadas com fungicidas foliares. O número de aplicações, se uma ou duas, e o tipo de fungicida não influenciaram o tamanho das lesões. A severidade da mancha-reticular foi pequena, especialmente sob tratamento de sementes. Evidenciou-se o efeito restritivo do tratamento de sementes sobre o crescimento das lesões, o qual é um componente importante de epidemias por manchas foliares em cevada.

Palavras-chave adicionais: Pyrenophora teres, Hordeum vulgare, controle.

\begin{abstract}
Lesion expansion of barley net blotch and its interaction with seed treatment

Field experiments were carried out at the FAMV/UPF, in 2002, to evaluate whether seed treatment with fungicides was able to influence the process of lesion expansion by barley (Hordeum vulgare) net blotch. Barley seeds of the cultivars BR 2 and MN 698 were treated with triadimenol at $40 \mathrm{~g}$ i.a./100 kg seeds. The seed treatment was combined with single or double sprays of a triazol fungicide (tebuconazole), or a triazol + strobyrulin (epoxiconazole + pyraclostrobin), at different plant growth stages. Lesion size and disease severity were assessed at 62, 79, 88, 95, 103, and 111 days after planting. The use of seeds with a low incidence of infection, seeds treated with fungicide, and foliar sprays significantly reduced the process of lesion expansion. The number of sprays, wheter one or two, and the type of fungicide did not influence lesion expansion. The severity of net blotch was low, especially under seed treatment, which reduced the process of lesion expansion, an important component of barley leaf spot epidemics.
\end{abstract}

Additional keywords: Pyrenophora teres, Hordeum vulgare, control.

\section{INTRODUÇÃO}

O processo de expansão de lesão tem sido referido como um importante componente do progresso de epidemias, especialmente quando as condições ambientais são desfavoráveis à esporulação, dispersão do inóculo e indução de novas infecções. Através da expansão das lesões já existentes, o tecido adjacente torna-se imediatamente infeccioso, enquanto novas infecções somente o fazem após um período de latência (Bergamin Filho \& Amorim, 1996; Berger et al., 1997).

O tamanho e a taxa de expansão da lesão têm sido mais utilizados para avaliar a resistência genética de cultivares e a agressividade de estirpes ou raças de bactérias e fungos

\footnotetext{
*Parte da Dissertação de Mestrado do primeiro autor. Universidade de Passo Fundo (2003).
}

fitopatogênicos (Johnson \& Taylor, 1976; Luo \& Zeng, 1995; Berger et al., 1997). Entretanto, como componente do processo epidêmico, a expansão de lesão deve ser considerada na definição de estratégias de controle para uma doença. As relações ou interações da expansão de lesão com o tratamento químico, por exemplo, são pouco conhecidas.

Recentemente, Menegon et al. (2002) verificaram que o aumento do tamanho das lesões da mancha-marrom e da mancha-reticular da cevada (Hordeum vulgare L.), causadas pelos fungos Bipolaris sorokiniana (Sacc. In. Sorok.) e Pyrenophora teres (Sacc.) Shoem., respectivamente, foi pouco ou nada influenciado pela aplicação de fungicidas após o estabelecimento da infecção. Por outro lado, aplicações preventivas impediram o estabelecimento de novas infecções por até 21 dias. Por este motivo, os autores sugerem que aplicações "quase-preventivas", realizadas aos primeiros 
sintomas das manchas foliares, exerceriam maior efeito sobre a expansão das lesões e sobre toda a epidemia, em relação àquelas iniciadas a partir de níveis de dano econômico.

O tratamento de sementes com fungicidas é comumente utilizado por produtores de cevada no Sul do Brasil. O objetivo principal do tratamento é reduzir a transmissão de fungos fitopatogênicos presentes nas sementes. Com a disponibilidade de modernos fungicidas sistêmicos de longo efeito residual, como o triadimenol e o fluquinconazole, tem sido possível proteger os estádios iniciais da cultura contra doenças foliares, tais como os oídios da cevada (Forcelini \& Reis, 1987) e do trigo (Triticum aestivum L.) (Forcelini \& Reis, 1988), a ferrugem do trigo (Picinini \& Fernandes, 1999), a mancha-reticular da cevada (Forcelini \& Reis, 1987) e a mancha-amarela do trigo (Picinini \& Fernandes, 1999).

A interação dos tratamentos de sementes e de parte aérea tem sido analisada com relação a alguns componentes da epidemia, tais como o tempo para aparecimento da doença, sua intensidade inicial, taxa de progresso diário e quantidade final. Não se tem maiores informações sobre o efeito desta interação no processo de expansão de lesão. Diante dos resultados obtidos por Menegon et al. (2002), é possível que o tratamento de sementes possa exercer algum efeito no sentido de limitar o crescimento das lesões, contribuindo assim para otimizar o controle e reduzir toda a epidemia. Com este trabalho, procurou-se avaliar como o tratamento de sementes, combinado com o de parte aérea, pode influenciar o processo de expansão de lesões por manchas foliares em cevada.

\section{MATERIAL E MÉTODOS}

O experimento foi instalado no campo experimental da FAMV/UPF, em 25/6/2002, com as cultivares BR 2 e MN 698, esta última com dois lotes diferentes de sementes, um proveniente de Passo Fundo (Lote A) e outro de Panambi (Lote B). As incidências de B. sorokiniana e P. teres foram de $17 \%$ e $2,5 \%$ no lote A e de $29 \%$ e $16,7 \%$ no B, respectivamente. A cultura da cevada foi estabelecida em sistema de semeadura direta, sobre palha de soja [Glycine max (L.) Merril], em área de rotação com aveia (Avena sativa L.).

$\mathrm{O}$ delineamento experimental foi o de parcelas casualizadas em blocos, com quatro repetições. Cada parcela constou de sete linhas de $10 \mathrm{~m}$, com espaçamento de $0,17 \mathrm{~m}$. Metade das sementes de cada cultivar e/ou lote foi tratada com o fungicida triadimenol (Baytan ${ }^{\circledR} 15 \mathrm{SC}, 270 \mathrm{ml}$ de p.c. $/ 100 \mathrm{~kg}$ de sementes). Todas as sementes foram tratadas com o inseticida imidacloprid (Gaucho ${ }^{\circledR}, 50 \mathrm{ml} / 100 \mathrm{~kg}$ sementes) para prevenção de insetos de solo e pulgões. Os tratos culturais foram realizados conforme as recomendações para a cultura da cevada (Comissão, 2001). A adubação foi com $230 \mathrm{~kg} / \mathrm{ha}$ da fórmula 5-20-20 (N-P-K).

Para gerar mais situações diferenciais quanto ao manejo das doenças, também se fez uso dos fungicidas foliares tebuconazole (Folicur ${ }^{\circledR}, 0,75 \mathrm{l} / \mathrm{ha}$ ), um composto triazol, e epoxiconazole + piraclostrobim $\left(\right.$ Opera ${ }^{\circledR}, 0,5$ l/ha), uma combinação de triazol com estrobilurina. Os fungicidas foram aplicados uma vez nos estádios de alongamento, emborrachamento ou florescimento, e duas vezes no alongamento e florescimento. As pulverizações foram realizadas utilizando-se um pulverizador costal, pressurizado com $\mathrm{CO}_{2}$, bicos do tipo DG 110015, ajustado para um volume de calda de 150 1/ha.

As manchas foliares foram avaliadas aos $62,79,88$, 95, 103 e 111 dias após a semeadura, através da coleta de dez plantas por parcela, cujas folhas foram analisadas quanto à porcentagem de severidade e ao tamanho das lesões. As lesões foram medidas quanto ao seu comprimento e largura, através de um paquímetro digital, com resolução de $0,01 \mathrm{~mm}$. Após a colheita, realizada em $09 / 11 / 02$, os grãos foram limpos, classificados e pesados para determinação do rendimento. Para comparação dos tratamentos utilizados, os dados de tamanho de lesão, severidade e rendimento de grãos foram submetidos à análise de variância, ao teste de $F$ e a contrastes ortogonais, utilizando-se o pacote estatístico disponível no aplicativo SAS, versão 6.12 .

\section{RESULTADOS}

Nos experimentos de campo realizados em 2002, a mancha-reticular foi a principal doença foliar observada na cevada, principalmente na cultivar MN 698, razão pela qual os resultados apresentados se referem a esta doença. Para simplificar a apresentação dos dados, os tratamentos utilizados na parte aérea foram agrupados em função do número de aplicações e do tipo de fungicida utilizado.

O tamanho da lesão (Figura 1 e Tabelas 1 e 2) foi influenciado significativamente pela incidência de sementes infetadas e pelos tratamentos da semente e da parte aérea com fungicidas, mas não pelo número de aplicações ou tipo de fungicida. No lote $\mathrm{B}$, com $16,7 \%$ de incidência por P. teres nas sementes, a área média das lesões (Figura 1), aos 79 e 88 dias após a semeadura, foi maior que a verificada no lote $\mathrm{A}$, com $2,5 \%$ de incidência do patógeno. Essa diferenciação não ocorreu quando as mesmas sementes foram tratadas com fungicida. Isso evidencia que o tratamento com o fungicida foi eficaz, controlando o fungo nas sementes. Na média de ambos os lotes, nas três avaliações realizadas, o tratamento de sementes resultou em lesões com tamanho significativamente menor. As diferenças em tamanho, entre as condições com e sem tratamento, se acentuaram com o passar do tempo.

A aplicação de fungicida na parte aérea (Tabela 1) reduziu o tamanho médio das lesões em relação às plantas que não foram tratadas. Isso ocorreu em ambas as situações, com e sem tratamento de sementes, sendo, porém, mais pronunciada nesta última. Na média das três avaliações realizadas, o tamanho médio das lesões variou de $8,0 \mathrm{~mm}^{2}$ (duas aplicações de fungicida) a $8,9 \mathrm{~mm}^{2}$ (uma aplicação) e $11,3 \mathrm{~mm}^{2}$ (testemunha sem fungicida). Não houve diferença significativa, quanto ao tamanho da lesão, entre uma ou duas aplicações de fungicida na parte aérea.

O tipo de fungicida utilizado na parte aérea (Tabela 2), 
Expansão de lesão da mancha-reticular da cevada e sua ...

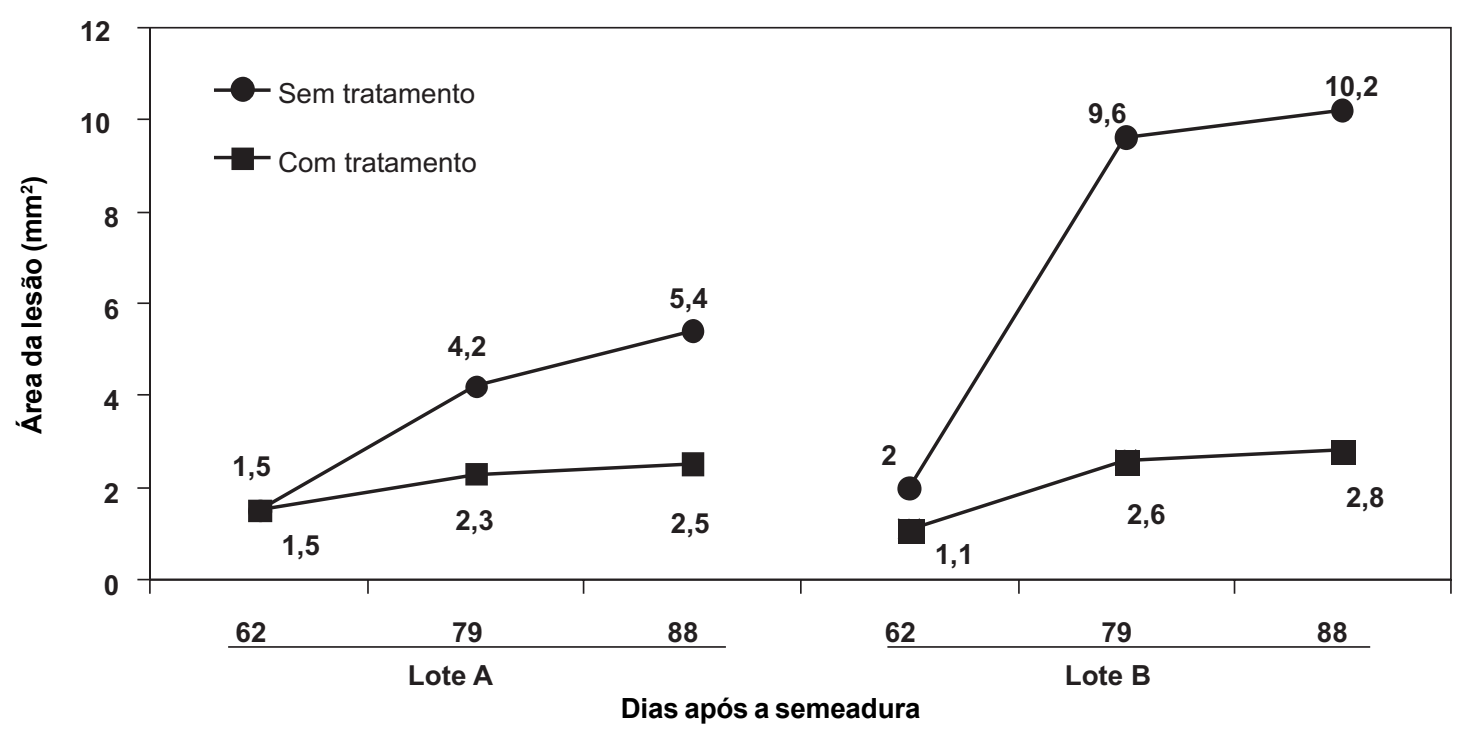

FIG. 1 - Área média $\left(\mathrm{mm}^{2}\right)$ de lesões da mancha-reticular, causada por Pyrenophora teres, em cevada (Hordeum vulgare) (cv. MN 698), com e sem tratamento de sementes com o fungicida triadimenol. A incidência do fungo era $2,5 \%$ no lote A e $16,7 \%$ no B. As diferenças atribuídas ao tratamento foram significativas pelo teste de $F(5 \%)$, exceto para o lote A, aos 62 dias após a emergência. FAMV/UPF, 2002.

TABELA 1 - Tamanho médio $\left(\mathrm{mm}^{2}\right)$ de lesões da mancha-reticular, causada por Pyrenophora teres, em cevada (Hordeum vulgare) (cv. MN 698), com (CTS) e sem (STS) tratamento de sementes, sob zero, uma ou duas aplicações de fungicida em parte aérea. FAMV/UPF, 2002

\begin{tabular}{|c|c|c|c|c|c|c|c|c|}
\hline \multirow{3}{*}{$\begin{array}{l}\text { Número de } \\
\text { aplicações }\end{array}$} & \multicolumn{8}{|c|}{ "Tamanho médio das lesões $\left(\mathrm{mm}^{2}\right)^{1}$} \\
\hline & \multicolumn{2}{|c|}{95 DAS $^{2}$} & \multicolumn{2}{|c|}{103 DAS } & \multicolumn{2}{|c|}{111 DAS } & \multicolumn{2}{|c|}{ Média } \\
\hline & CTS & STS & CTS & STS & CTS & STS & CTS & STS \\
\hline 0 & $4,5 \mathrm{a}^{3}$ & $9,7 \mathrm{a}$ & $5,1 \mathrm{a}$ & $11,8 \mathrm{a}$ & $4,6 \mathrm{a}$ & $12,6 \mathrm{a}$ & 4,7 & 11,3 \\
\hline 1 & $3,6 \mathrm{~b}$ & $6,0 \mathrm{~b}$ & $3,9 \mathrm{~b}$ & $9,9 \mathrm{~b}$ & $3,5 \mathrm{~b}$ & $10,8 \mathrm{~b}$ & 3,7 & 8,9 \\
\hline 2 & $3,3 \mathrm{~b}$ & $5,3 \mathrm{~b}$ & $3,3 \mathrm{~b}$ & $8,9 \mathrm{~b}$ & $2,9 \mathrm{~b}$ & $9,7 \mathrm{~b}$ & 3,2 & 8,0 \\
\hline
\end{tabular}

${ }^{1}$ Média de dois lotes de sementes;

${ }^{2}$ Dias após a semeadura;

${ }^{3}$ Médias com letras iguais não diferem entre si por contrastes ortogonais.

TABELA 2 - Tamanho médio $\left(\mathrm{mm}^{2}\right)$ de lesões da mancha-reticular, causada por Pyrenophora teres, em cevada (Hordeum vulgare) (cv. MN 698), com (CTS) e sem (STS) tratamento de sementes, sob a aplicação de dois tipos de fungicida em parte aérea. FAMV/UPF, 2002

\begin{tabular}{|c|c|c|c|c|c|c|c|c|}
\hline \multirow{3}{*}{$\begin{array}{l}\text { Tipo de } \\
\text { fungicida }\end{array}$} & \multicolumn{8}{|c|}{ Tamanho médio das lesões $\left(\mathrm{mm}^{2}\right)^{1}$} \\
\hline & \multicolumn{2}{|c|}{$95 \mathrm{DAS}^{2}$} & \multicolumn{2}{|c|}{103 DAS } & \multicolumn{2}{|c|}{111 DAS } & \multicolumn{2}{|c|}{ Média } \\
\hline & CTS & STS & CTS & STS & CTS & STS & CTS & STS \\
\hline Testemunha & $4,4 a^{3}$ & $9,7 \mathrm{a}$ & $5,1 \mathrm{a}$ & $11,8 \mathrm{a}$ & $4,6 \mathrm{a}$ & $12,6 \mathrm{a}$ & 4,7 & 11,3 \\
\hline Triazol & $3,5 \mathrm{~b}$ & $5,9 \mathrm{~b}$ & $3,7 \mathrm{~b}$ & $9,4 \mathrm{~b}$ & $3,3 \mathrm{~b}$ & $10,2 \mathrm{~b}$ & 3,5 & 8,5 \\
\hline Tria + est $^{4}$ & $3,4 \mathrm{~b}$ & $5,5 \mathrm{~b}$ & $3,5 \mathrm{~b}$ & $9,6 \mathrm{~b}$ & $3,3 \mathrm{~b}$ & $10,4 \mathrm{~b}$ & 3,4 & 8,5 \\
\hline
\end{tabular}

${ }^{1}$ Média de dois lotes de sementes;

${ }^{2}$ Dias após a semeadura;

${ }^{3}$ Médias com letras iguais não diferem entre si por contrastes ortogonais;

${ }^{4}$ Triazol (tebuconazole); triazol + estrobilurina (epoxiconazole + piraclostrobim).

triazol ou triazol + estrobilurina, não influenciou o tamanho médio das lesões. Novamente, as diferenças existiram apenas quando os tratamentos foram comparados com a testemunha sem fungicida.
Os percentuais de severidade da doença, ao longo de 111 dias após a semeadura, foram baixos, tendo atingido um máximo de $0,56 \%$. Por este motivo, as diferenças entre as médias dos tratamentos não foram significativas. Contudo, 
em todas as avaliações realizadas, na presença ou ausência da aplicação de fungicidas na parte aérea, as plantas oriundas de sementes tratadas tenderam a apresentar menor severidade de doença.

\section{DISCUSSÃO}

Em trabalhos com tratamento de sementes de cereais de inverno, especialmente os realizados por Forcelini \& Reis (1987) em cevada e Picinini \& Fernandes (1999) em trigo, ficou evidente que certos fungicidas sistêmicos tem a propriedade de atrasar o desenvolvimento inicial de manchas foliares e reduzir sua intensidade final. Apesar do tratamento de sementes atuar, predominantemente, na redução do inóculo inicial que dá origem a uma doença (Berger, 1977), esta estratégia de controle também atrasa o início da epidemia e diminui a sua taxa de progresso diário (Ballico, 2002). Segundo Bergamin Filho \& Amorim (1996), o progresso de uma doença, mensurado através da sua taxa, pode ser explicado pelo surgimento de novas lesões e pela expansão daquelas já existentes.

Neste trabalho com a mancha-reticular da cevada, o tratamento de sementes com fungicidas sistêmicos reduziu o tamanho inicial e final das lesões, efeito que foi significativo até 111 dias após a semeadura. Assim, verifica-se que parte importante do efeito do tratamento de sementes sobre as manchas foliares da cevada deve-se a sua ação inibitória sobre o crescimento das lesões, e que esta ação pode ser obtida mesmo com quantidades residuais pequenas de fungicida nas folhas. Explica-se, assim, uma das formas pelas quais o tratamento de sementes reduz a taxa de progresso da doença.

Como esta segunda via, alternativa, de crescimento da doença, através da expansão da lesão, ocorre principalmente quando as condições são desfavoráveis à esporulação pelo patógeno (Bergamin Filho \& Amorim, 1996), esse efeito do tratamento de sementes em relação ao crescimento da lesão deverá produzir maior impacto sobre a epidemia em períodos com pouca freqüência de chuvas, reduzida ocorrência de orvalho sobre as folhas ou baixa umidade relativa do ar.

\section{REFERÊNCIAS BIBLIOGRÁFICAS}

BALLICO, L.J. Controle integrado da ferrugem da folha em aveia. (Dissertação de Mestrado). Passo Fundo. Universidade de Passo Fundo. 2002.

BERGAMIN FILHO, A. \& AMORIM, L. Doenças de plantas tropicais: epidemiologia e controle econômico. São Paulo. Ed. Agronômica Ceres. 1996.

BERGER, R.D. Application of epidemiological principles to achieve plant disease control. Annual Review of Phytopathology 15:165183. 1977.

BERGER, R.D., BERGAMIN FILHO, A. \& AMORIM, L. Lesion expansion as an epidemic component. Phytopathology 87:1005-1013. 1997.

COMISSÃO DE PESQUISA DE CEVADA. Indicações técnicas para produção de cevada cervejeira: safras 2001 e 2002. Passo Fundo. Embrapa Trigo. 2001.

FORCELINI, C.A. \& REIS, E.M. Efeito do tratamento de sementes de cevada com fungicidas no controle e desenvolvimento da mancha reticulada da folha causada por Helminthosporium teres Sacc. (=Pyrenophora teres Drech.) Fitopatologia Brasileira 12: 83-87. 1987.

FORCELINI, C.A. \& REIS, E.M. Controle de Helminthosporium sativum, Septoria nodorum, Fusarium graminearum e Erysiphe graminis tritici pelo tratamento de sementes de trigo com fungicidas. Fitopatologia Brasileira 13:28-31. 1988.

JOHNSON, R. \& TAYLOR, A.J. Spore yield of pathogens in investigations of the race-specificity of host resistance. Annual Review of Phytopathology 14:97-119. 1976.

LUO, Y. \& ZENG, S.M. Simulation studies on epidemics of wheat stripe rust (Puccinia striiformis) on slow-rusting culivars and analysis of effects of resistance components. Plant Pathology 44:340349. 1995.

MENEGON, A.P., WESP, C., FORCELINI, C.A. \& FERNANDES, J.M.C. Expansão de lesão por manchas foliares em cevada. Anais e ata, XXII Reunião Aual de Pesquisa de Cevada, Passo Fundo, RS. 2002. pp.541-548.

PICININI, E.C. \& FERNANDES, J.M.C. Efeito de fungicidas no controle in vitro e in vivo de Bipolaris sorokiniana e de Fusarium graminearum. Anais, XIX Reunião Anual de Pesquisa de Cevada, Passo Fundo, RS. 1999. pp.418-422. 